\title{
Laparoscopic transgastric resection of gastric submucosal tumor located near the esophagogastric junction
}

\author{
Pablo Priego, Marta Cuadrado, Francisca García-Moreno, Pedro Carda, Julio Galindo \\ Division of Upper \& GI, Bariatric and Minimally Invasive Surgery, Department of Surgery, Ramón y Cajal University Hospital, Madrid \\ 28034, Spain.
}

Correspondence to: Dr. Pablo Priego, Division of Upper \& GI, Bariatric and Minimally Invasive Surgery, Department of Surgery, Ramón y Cajal University Hospital, Crta. De Colmenar Viejo Km 9,100, Madrid 28034, Spain. E-mail: papriego@hotmail.com

How to cite this article: Priego P, Cuadrado M, García-Moreno F, Carda P, Galindo J. Laparoscopic transgastric resection of gastric submucosal tumor located near the esophagogastric junction. Mini-invasive Surg 2018;2:6.

http://dx.doi.org/10.20517/2574-1225.2018.01

Received: 9 Jan 2018 First Decision: 26 Feb 2018 Revised: 3 Mar 2018 Accepted: 6 Mar 2018 Published: 8 Apr 2018

Science Editor: Fernando A. M. Herbella Copy Editor: Jun-Yao Li Production Editor: Huan-Liang Wu

\begin{abstract}
Aim: Laparoscopic wedge resection is widely accepted as the choice of treatment for gastric submucosal tumors (GST). However, tumors on the posterior wall at the esophagogastric junction (EGJ) are difficult to approach. Laparoscopic transgastric resection (LTR) is a novel technique to remove gastric tumors that are unresectable by endoscopy due to their size and location. The aim of the article is to assess the feasibility and oncological outcomes of this laparoscopic approach for intraluminal GST located in the posterior wall and near the EGJ.
\end{abstract}

Methods: A retrospective analysis of all patients with GST located at the EGJ who underwent LTR at our institution from January 2015 to February 2016 was performed.

Results: Of the 4 patients who underwent LTR, 3 were female and 1 was male, with a mean age of 74.5 years. LTR was successfully performed in all the cases. All patients received a complete resection with negative margins. Histopathologic diagnoses were gastrointestinal stromal tumor in 2 cases and leiomyoma in the other 2. Median tumor size was $3.45 \mathrm{~cm}$. The mean operation time was $173 \mathrm{~min}$ (range 120-232 min). One patient experienced a postoperative hematemesis, but was treated conservatively. The mean postoperative stay was 8 days (range 4-15 days).

Conclusions: LTR is feasible and difficult localizations can be reached with ease. It is an appropriate alternative to laparoscopic wedge resections especially for localizations that cannot be accessed by laparoscopy such as tumors located near the EGJ.

Keywords: Gastrointestinal stromal tumors, esophagogastric junction, transgastric resection, laparoscopy, gastric submucosal tumors, laparoscopic

cC) (i) (c) The Author(s) 2018. Open Access This article is licensed under a Creative Commons Attribution 4.0 International License (https://creativecommons.org/licenses/by/4.0/), which permits unrestricted use, sharing, adaptation, distribution and reproduction in any medium or format, for any purpose, even commercially, as long as you give appropriate credit to the original author(s) and the source, provide a link to the Creative Commons license, and indicate if changes were made.

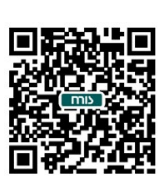




\section{INTRODUCTION}

Gastric submucosal tumors (GST) are rare, accounting for $<1 \%$ of gastrointestinal tumors. Currently, surgical resection remains the only chance for cure ${ }^{[1]}$.

Laparoscopic wedge resection is widely accepted as a choice of treatment for GST especially for tumors in the anterior wall, lesser curvature, and greater curvature. However, the difficulty in accessing tumors located in the posterior wall and esophagogastric junction (EGJ) requires alternative approaches ${ }^{[1]}$.

Laparoscopic transgastric resection (LTR) is a novel technique of removing gastric tumors that are unresectable by endoscopy due to their size and location. However, there are limited reports on this technique as this clinical entity occurs rarely ${ }^{[1-5]}$.

The aim of the article is to assess feasibility and oncological outcomes of the laparoscopic approach for intraluminal GST located in the posterior wall and near the EGJ.

\section{METHODS}

A retrospective analysis of all patients with GST located at the EGJ underwent LTR at our institution from January 2015 to February 2016 was performed.

Patient demographics, preoperative symptoms, imaging studies, operative data, complications, hospital stay, and follow-up were analyzed.

\section{Preoperative, postoperative and long-term clinical assessment}

All the patients underwent a standard preoperative workup including physical examination, blood analysis, chest X-ray, upper gastrointestinal barium meal X-ray study, oral endoscopy, eco-endoscopy and computerized tomography scan [Figure 1].

Postoperatively, patients were placed on a clear liquid diet and discharged home on a soft diet. Follow-up was performed approximately 1, 2, 4 weeks, the 6 th and 12th months, then every year after surgery where an oral endoscopy was performed.

Histopathologic diagnoses were gastrointestinal stromal tumor (GIST) in 2 cases and leiomyoma in the other 2. Median tumor size was $3.45 \mathrm{~cm}$ (range 2.3-5.5 cm).

\section{Patient's position and trocar's placement}

The surgery was performed with the patient under general anesthesia and placed in a modified lithotomy position. The surgeon stood between the patient's legs with the camera surgeon on the patient's right side and the assistant on the left.

A four-port technique was employed in the upper abdomen: epigastric 5-mm ballon trocar, left midclavicular 10-mm ballon trocar, left hipocondrium 12-mm ballon trocar and supraumbilical 10-mm trocar (Applied Medical). Nathanson liver retractor was used in selected cases when the upper part of stomach was covered with bulky liver [Figure 2].

\section{Gastric wall incision and intragastric trocar insertion}

Pneumoperitoneum was created with Veress needle in left upper hypocondrium and carbon dioxide was insufflated to maintain the intra-abdominal pressure at 10-12 $\mathrm{mmHg}$. A $30^{\circ}$-degree laparoscope was used. 

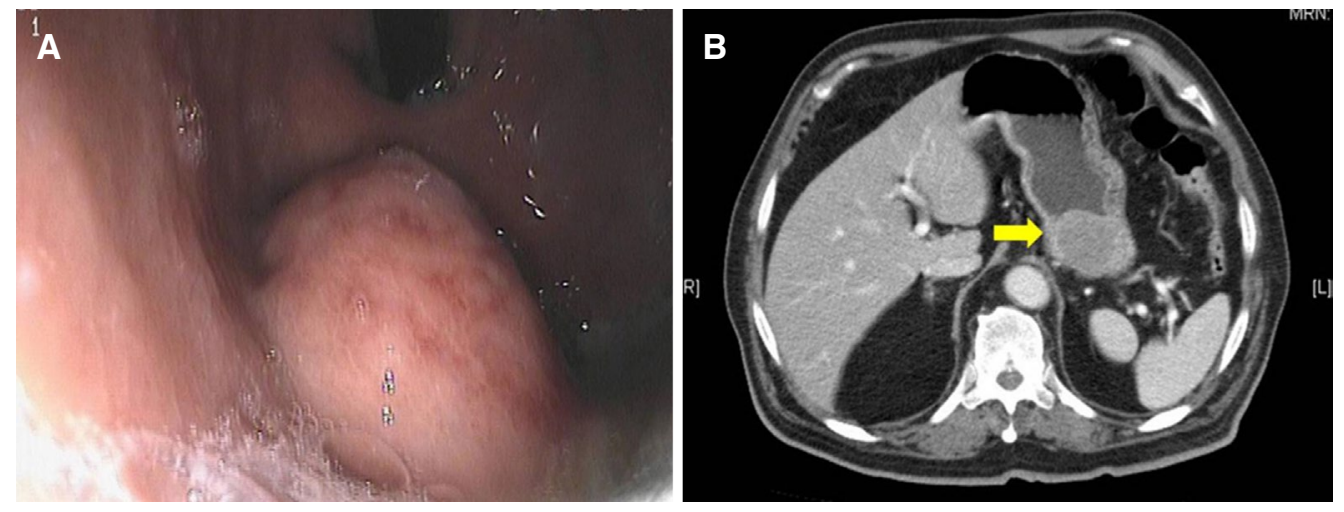

Figure 1. Gastrointestinal stromal tumor near the esophagogastric junction observed in oral endoscopy (A) and computerized tomography scan (B)

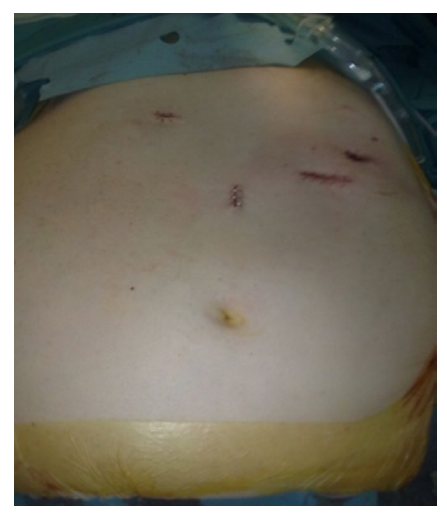

Figure 2. Trocar placement

First, we started the procedure after inserting a supraumbilical 10-mm port. A second 10-mm ballon trocar was placed along the left midclavicular line and a third port, sized 5-mm ballon trocar was placed along the epigastric line, under direct vision.

The procedure started with the incision of a suitable point on the gastric wall, which served for the introduction of a $12-\mathrm{mm}$ balloon trocar. This step was performed using the Ultracision [Figure 3A]. This trocar was used to allow the introduction of a 10-mm scope and also to allow the sealing of the stomach to the abdominal wall. The other 10 and $5 \mathrm{~mm}$ balloon trocars were inserted into the stomach [Figure $3 \mathrm{~B}$ ].

\section{Tumor resection}

Once balloon trocars were inside stomach, pneumogastrum was established (4-6 mmHg).The location of the tumor was confirmed after the introduction of the scope [Figure 4A]. For tumors near the EGJ, precaution was taken not to involve the EGJ itself. For that, the EGJ needed to be clearly identified either by insertion of the tip of a nasogastric tube or a gastroscope. To facilitate the resection, sometimes we used a tractive suture into the tumor. The resection was performed by means of the Ultracision (Harmonic Scalpel; Ethicon Endo-Surgery, Cincinnati, OH, USA), making sure to leave a 1-cm of clear tissue around the lesion without breach of the capsule [Figure 4B]. Once the tumor has been removed, we introduced an Endobag, and retrieved the specimen through the ballon trocar.

\section{Closure of the gastric defect}

A single layer of interrupted sutures with non-absorbable material (Ethibond 2/0) was used to closure the posterior gastric wall [Figure 5]. The trocar was then be retrieved under vision and the anterior gastric wall sutured with interrupted Ethibond 2/0 suture. A methylene blue test was performed in order to exclude gastric leaks. 

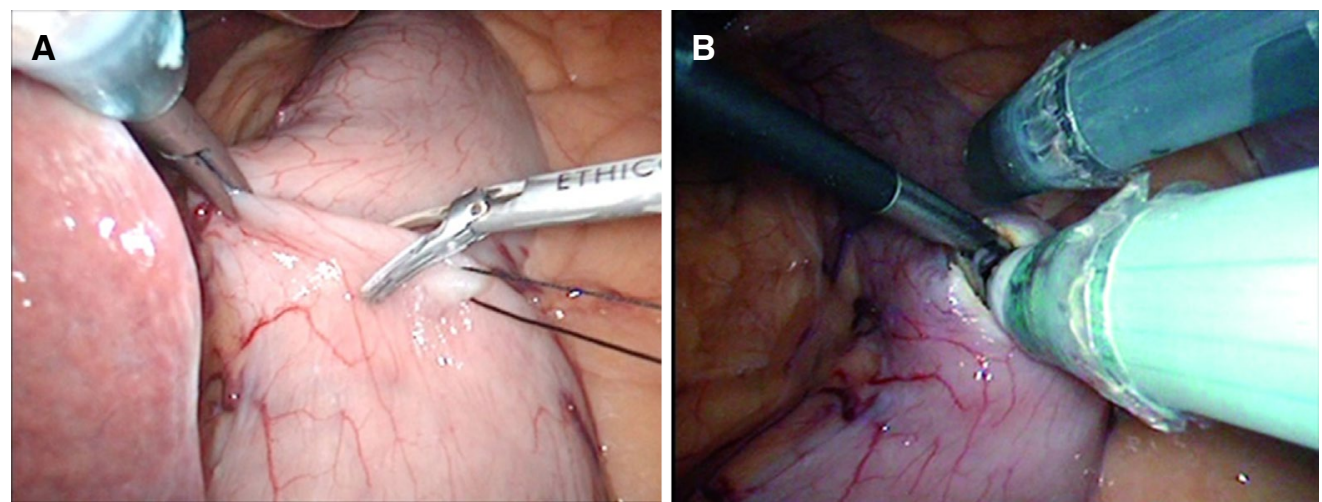

Figure 3. (A) Suitable point on the gastric wall. Open of stomach; (B) introduction of balloon trocar inside stomach
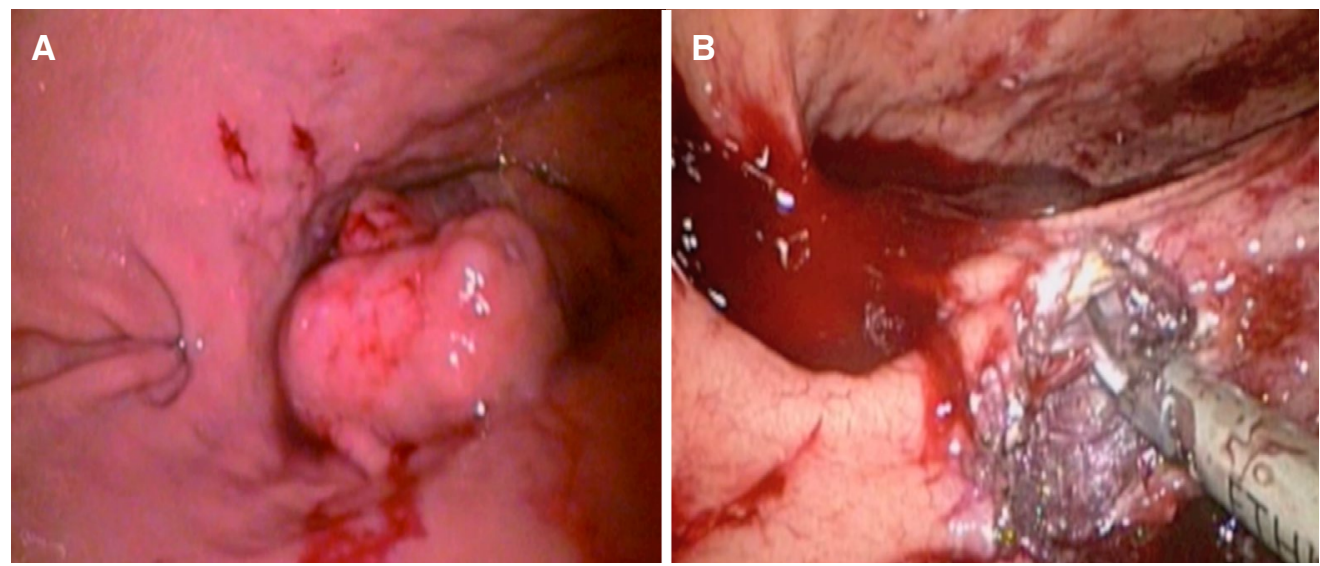

Figure 4. (A) Submucosal stromal tumor near the esophagogastric junction; (B) resection of gastric submucosal tumor with Ultracision

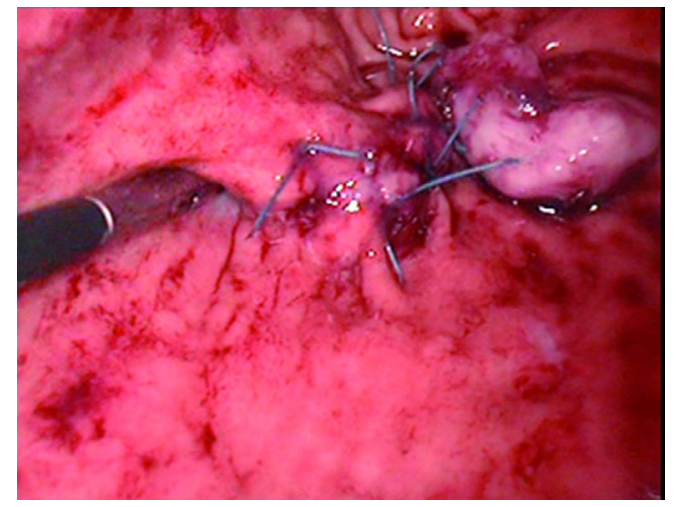

Figure 5. Closure of the defect

No drains were normally used but a nasogastric tube was maintained overnight.

\section{RESULTS}

Of the 4 patients who underwent LTR, 3 were female and 1 was male, with a mean age of 74.5 years (range 64-82 years). Demographics and tumor characteristics were described in Table 1.

LTR was successfully performed on all the cases. All patients received complete resection with a negative margin. 
Table 1. Demographic characteristics of patients

\begin{tabular}{|c|c|c|c|c|}
\hline & Case 1 & Case 2 & Case 3 & Case 4 \\
\hline Age (year)/gender & $82 / \mathrm{M}$ & $74 / F$ & $78 / \mathrm{F}$ & $64 / F$ \\
\hline ASA & III & II & II & III \\
\hline Comorbidities & COPD, DM & Hypertension & Hypertension, DM, DL & $\begin{array}{l}\text { Hypertension, dilated } \\
\text { myocardiopathy, } \\
\text { ischemic cerebrovascular } \\
\text { accident }\end{array}$ \\
\hline Symptoms & Haematemesis & Haematemesis & Epigastric pain & Epigastric pain \\
\hline Diagnosis & $\begin{array}{l}\text { Endoscopy, } \\
\text { CT scan }\end{array}$ & $\begin{array}{l}\text { Endoscopy, } \\
\text { Eco-endoscopy, } \\
\text { CT scan }\end{array}$ & $\begin{array}{l}\text { Endoscopy, } \\
\text { Eco-endoscopy, } \\
\text { CT scan, } \\
\text { Barium swallow } \\
\text { MRI }\end{array}$ & $\begin{array}{l}\text { Endoscopy, } \\
\text { Eco-endoscopy, } \\
\text { CT scan }\end{array}$ \\
\hline Hystopathology & $\begin{array}{l}\text { GIST low malignancy, } \\
\text { mitotic index }<5 / 50\end{array}$ & $\begin{array}{l}\text { GIST low malignancy, mitotic } \\
\text { index } \\
<5 / 50\end{array}$ & Leiomyoma & Leiomyoma \\
\hline Size tumor $(\mathrm{cm})$ & 5.5 & 3 & 3 & 2.3 \\
\hline Operative time (min) & 120 & 195 & 145 & 232 \\
\hline Intraoperative complications & None & None & None & Methilene blue leakage \\
\hline Postoperative complications & None & None & None & Fever, haematemesis \\
\hline Oral intake (days) & 3 & 2 & 3 & 10 \\
\hline Hospital stay (days) & 7 & 4 & 6 & 15 \\
\hline Mortality & No & No & No & No \\
\hline
\end{tabular}

M: male; F: female; ASA: American Society of Anesthesiologists; COPD: chronic obstructive pulmonary disease; DM: diabetes mellitus; CT: computerized tomography; GIST: gastrointestinal stromal tumors; DL: dyslipemia; MRI: magnetic resonance imaging

The mean operation time was $173 \mathrm{~min}$ (range 120-232 $\mathrm{min}$ ). There were no conversions. There were no intraoperative complications, but in one of the patients, a methylene blue leakage was observed when suture was checked, which was reinforced. No postoperative complications were described, but patient with methylene blue leakage experimented hyperpyrexia in the first $24 \mathrm{~h}$ after operation and haematemesis. Both problems were treated conservatively.

The mean postoperative stay was 8 days (range 4-15 days). There was no death in our series.

At a mean follow-up of 31 months, all of our patients are asymptomatic and free of recurrence. None showed evidence of stenosis of the EGJ or acid reflux symptoms.

\section{DISCUSSION}

Laparoscopic wedge resection is widely accepted as a choice of treatment for GST, especially for tumors in the anterior wall, lesser curvature, and greater curvature. However, tumors on the posterior wall at the EGJ remain difficult to approach $^{[1-5]}$.

Privette et al. ${ }^{[6]}$ proposed a tailored location-based standardized approach to resection of gastric GIST. This new classification on the basis of tumor location considers type 1 tumors located in fundus and greater curvature, type 2 for tumors in the antrum-prepyloric region and type 3 for tumors in the lesser curvature and EGJ. The surgical approach as dictated by tumor location would be a laparoscopic wedge resection for type 1, a laparoscopic distal gastrectomy for large type 2 tumors, and a laparoscopic transgastric resection for type 3.

The optimal approach to GISTs located near EGJ is not well defined. Such tumors have been reported as the reason for conversion, planned open procedure, and exclusion indication for laparoscopic approach ${ }^{[7]}$.

Several laparoscopic approaches have been described for the surgical treatment of gastric GIST near the 
EGJ or posterior wall. These approaches include tumor enucleation, exogastric wedge resection, transgastric tumor-everting resection, intragastric tumor everting resection, laparoscopic and endoscopic cooperative surgery and esophagogastrectomy ${ }^{[8-11]}$.

Laparoscopic transgastric resection of GST was first described by Geis et al ${ }^{[12]}$. Several publications of this technique have shown the procedure to be feasible and safe with good outcomes in the resection of GISTs located near EGJ, posterior wall and the antropyloric region ${ }^{[1-5]}$. However, certain principles need to be practiced when performing this intervention.

First, this procedure requires greater expertise and laparoscopic skills, so whether you want to follow strict oncological outcomes, this surgery should be only performed in hands of experienced surgeons with advanced laparoscopic skills.

In our experience, we advise the use of ballon trocars in order to minimize the leakage of pneumogastrum during the resection of the tumor. Moreover, we consider trocar placement as the key of a successfully resection. In fact, before introducing any trocar, when the upper part of stomach is covered by bulky liver,we first introduce a Nathanson liver retractor in order to define the anatomy. It is important to put the trocars as high as possible, and to introduce the left balloon trocar in the midline of the epigastrium in order to reduce the distance between the abdominal and gastric wall.

We have not used any system of occlusion of duodenum to maintain air-inflated stomach, and we have not had any problem during resection of the tumors.

Another important step is avoiding EGJ stenosis, especially when an endoscopic linear stapler is used to remove the specimen. In addition, one needs to confirm if the EGJ is intact prior to firing, either with the position of a nasogastric tube or a gastroscope.

Most authors utilized the technique of transgastric stapled resection as it allows simultaneous resection and closure of the defect in the stomach. In our series, we have preferred the use of ultrasonic device to remove the tumor because it is feasible to manipulate and to avoid bleeding. With the stapling, overall operating time would be shortened, because it was not require closing the gastric wall with suture. Finally, we have only had one intraoperative complication using this technique. In one patient, a methylene blue leakage was observed when the suture line was checked, requiring reinforced.

Caution need to be taken to minimize tumor handling in order to prevent tumor rupture or spillage. It is advisable to avoid grasping the center of the tumor, but instead to grasp the normal mucosal surrounding it. For this reason and also to facilitate the resection, sometimes we use a suture into the tumor for retraction.

Moreover, it is important to achieve good haemostasis during the surgery, avoiding using suction and irrigation in order to maintain air-inflated in the stomach.

In conclusion, and if these principles are followed, laparoscopic transgastric resection seems to be a safe and effective procedure for gastric submucosal tumors located near the esophagogastric junction. However, advancedtraining in laparoscopic surgery is advised.

\section{DECLARATIONS}

\section{Authors' contributions}

Study conception and design, drafting of manuscript: Priego P

Data collection: Cuadrado M, García-Moreno F

Analysis and interpretation of results, critical revision: Carda P, Galindo J 


\section{Financial support and sponsorship}

None.

\section{Data source and availability}

All data are stored in the computer lab of Department of General Surgery at Ramon y Cajal University Hospital.

\section{Conflicts of interest}

There are no conflicts of interest.

\section{Patient consent}

Informed consent was obtained from all patients for being included in the study.

\section{Ethics approval}

Study was approved by Local Ethics Committee.

\section{Copyright}

(C) The Author(s) 2018 .

\section{REFERENCES}

1. Xu X, Chen K, Zhou W, Zhang R, Wang J, Wu D, Mou Y. Laparoscopic transgastric resection of gastric submucosal tumors located near the esophagogastric junction. J Gastrointest Surg 2013;17:1570-5.

2. Liao YT, Yang CY, Lai IR, Chen CN, Lin MT. Laparoscopic resection for submucosal tumors near the esophagogastric junction: feasibility and short-term outcome. Surg Innov 2013;20:478-83.

3. Siow SL, Mahendran HA, Wong CM. Laparoscopic transgastric resection for intraluminal gastric gastrointestinal stromal tumors located at the posterior wall and near the gastroesophageal junction. Asian J Surg 2017;40:407-14.

4. Ma JJ, Hu WG, Zang L, Yan XW, Lu AG, Wang ML, Li JW, Feng B, Zhong J, Zheng MH. Laparoscopic gastric resection approaches for gastrointestinal stromal tumors of stomach. Surg Laparosc Endosc Percutan Tech 2011;21:101-5.

5. Vazquez AM, Hernández A, Bertomeu A, Ruiz de Adana JC. Cirugía laparoscópica intragástrica: una opción en lesiones gástricas no resecables endoscópicamente. Cir Esp 2016;94:175-8.

6. Privette A, Mc Cahill L, Borrazo E, Single RM, Zubarik R. Laparoscopic approaches to resection of suspected gastric gastrointestinal stromal tumors based on tumor location. Surg Endosc 2008;22:487-94.

7. Lee CH, Hyun MH, Kwon YJ, Cho SI, Park SS. Deciding laparoscopic approaches for wedge resection in gastric submucosal tumors: a suggestive flow chart using three major determinants. J Am Coll Surg 2012;215:831-40.

8. Ntourakis D, Mavrogenis G. Cooperative laparoscopic endoscopic and hybrid laparoscopic surgery for upper gastrointestinal tumors: current status. World J Gastroenterol 2015;21:12482-97.

9. Lamm SH, Steinemann DC, Linke GR, Eucker D, Simon T, Zerz A, Stoll R. Total inverse transgastric resection with transoral specimen removal. Surg Endosc 2015;29:3363-6.

10. Barajas-Gamboa JS, Acosta G, Savides TJ, Sicklick JK, Fehmi SM, Coker AM, Green S, Broderick R, Nino DF, Harnsberger CR, Berducci MA, Sandler BJ, Talamini MA, Jacobsen GR, Horgan S. Laparo-endoscopic transgastric resection of gastric submucosal tumors. Surg Endosc 2015;29:2149-57.

11. Wilhelm D, von Delius S, Burian M, Schneider A, Frimberger E, Meining A, Feussner H. Simultaneous use of laparoscopy and endoscopy for minimally invasive resection of gastric subepithelial masses - analysis of 93 interventions. World J Surg 2008;32:1021-8.

12. Geis WP. Baxt R, Kim HC. Benign gastric tumors. Minimally invasive approach. Surg Endosc 1996;10:407-10. 